\title{
Article \\ Alcohol Abuse and Insomnia Disorder: Focus on a Group of Night and Day Workers
}

\author{
Fulvio Plescia ${ }^{1, *(\mathbb{D})}$, Luigi Cirrincione ${ }^{1}$, Daniela Martorana ${ }^{2}$, Caterina Ledda ${ }^{3}{ }^{(0)}$, Venerando Rapisarda ${ }^{3}{ }^{(0}$, \\ Valentina Castelli ${ }^{4}$, Francesco Martines ${ }^{4}$, Denis Vinnikov ${ }^{5}$ (i) and Emanuele Cannizzaro ${ }^{1, *}$ (i)
}

1 Department of Health Promotion Sciences Maternal and Child Care, Internal Medicine and Medical Specialties "Giuseppe D'Alessandro", University of Palermo, Via del Vespro 133, 90127 Palermo, Italy; luigicirrincione@gmail.com

2 Department of Orthopaedic Surgery, Azienda Ospedaliera "Ospedali Riuniti Villa Sofia Cervello", 90146 Palermo, Italy; dani.m@hotmail.it

3 Department of Clinical and Experimental Medicine, Occupational Medicine, University of Catania, 95123 Catania, Italy; cledda@unict.it (C.L.); vrapisarda@unict.it (V.R.)

4 Department of Biomedicine, Neuroscience and Advanced Diagnostics (BiND), Section of Audiology, University of Palermo, Via del Vespro, 129, 90127 Palermo, Italy; valentina.castelli02@unipa.it (V.C.); francesco.martines@unipa.it (F.M.)

5 Faculty of Medicine and Healthcare, Al-Farabi Kazakh National University, Al-Farabi Avenue 71, Almaty 050040, Kazakhstan; denisvinnikov@mail.ru

* Correspondence: fulvio.plescia@unipa.it (F.P.); emanuele.cannizzaro@unipa.it (E.C.); Tel.: +39-23865715 (F.P.)

\section{check for} updates

Citation: Plescia, F.; Cirrincione, L.; Martorana, D.; Ledda, C.; Rapisarda, V.; Castelli, V.; Martines, F.; Vinnikov, D.; Cannizzaro, E. Alcohol Abuse and Insomnia Disorder: Focus on a Group of Night and Day Workers. Int. J. Environ. Res. Public Health 2021, 18, 13196. https://doi.org/10.3390/ ijerph182413196

Academic Editors: Daniela Tempesta and Maria Esposito

Received: 18 October 2021

Accepted: 11 December 2021

Published: 14 December 2021

Publisher's Note: MDPI stays neutral with regard to jurisdictional claims in published maps and institutional affiliations.

Copyright: (c) 2021 by the authors. Licensee MDPI, Basel, Switzerland. This article is an open access article distributed under the terms and conditions of the Creative Commons Attribution (CC BY) license (https:// creativecommons.org/licenses/by/ $4.0 /)$.
Abstract: The sleep-wake cycle plays a fundamental role in maintaining the physiological balance of our body. Its alteration favours the genesis of several organic alterations and diseases including sleep disorders and the consumption of several substances of abuse. It has been reported that the work activity, especially that carried out during the night, is able to influence the sleep-wake cycle, promoting the development of insomnia, which, in turn, would subject the worker to a stressful condition such as to encourage adverse behaviour such as the use/abuse of psychotropic substances. Based on the above premises, the aim of our research was to evaluate, in night workers: (i) the pattern of consumption of alcoholic beverages; (ii) the presence of insomnia; and (iii) the possible correlation between alcohol consumption and insomnia disorder. We used the AUDIT-C test (the abbreviated version of the Alcohol Use Disorders Identification Test) and the Insomnia Severity Index to assess alcohol consumption and insomnia disorder, respectively. All questionnaires were completed by workers of both sexes belonging to different types of work activities, exclusively day or night. The results of our research show a higher propensity of night workers to consume alcoholic beverages than those who work during daytime hours, often in binge-drinking mode. In addition, an increase in the amount of alcohol consumed was found to be related to insomnia disorder, especially in night workers. This study provides further awareness of the importance of the negative impact of alcohol consumption on sleep quality in night workers.

Keywords: alcohol; sleep disorders; night workers; AUDIT-C

\section{Introduction}

The sleep-wake cycle plays a key role in the genesis of several mental disorders such as post-traumatic stress disorder (PTDS), straining, depression, anxiety, and is also associated with sleep disorders and substance abuse. [1-6]. Sleep disorders include disturbances in sleep initiation and sleep maintenance which, in turn, may adversely affect chronic disease outcomes by increasing related mortality and morbidity [7-12]. For example, obstructive sleep apnea syndrome, now recognized as one of the most frequent causes of excessive daytime sleepiness, has been identified as a contributing or contributing factor or cofactor in a significant number of work-related accidents [13]. 
It has been reported that there is a bidirectional relationship between sleep disorders and serious medical conditions, which are commonly related to work and age. People suffering from sleep disorders are usually more prone to develop hypertension, depression, cardiovascular and cerebrovascular diseases; conversely, individuals with any of these clinical conditions or with olfactory dysfunction and chronic nasal disorders are at a higher risk than healthy individuals of developing sleep-related problems [14-19]. In this regard, different types of work activities seem to influence the onset of diseases related to an alteration of the sleep-wake cycle, also in relation to the continuous increase in stress conditions, of the work environment, related to the recent pandemic from Sars-CoV 2 that has also invested the world of work [20-23].

In particular, night work (all work activities performed during a period of no less than three consecutive hours, from midnight to 5:00 a.m.) seems to have harmful effects on people's ability to adapt to the natural cycles of light and darkness and, consequently, could play a critical role in the genesis of several health problems such as cardiovascular diseases, gastrointestinal diseases and sleep disorders [24-26]. Regarding this, it is worth mentioning that night work and work-related stress are assessed in the Risk Assessment Document with a combined multidisciplinary approach and are the subject of health promotion campaigns and periodic training in the workplace [27-29].

In recent years, many researchers have focused on the relationship between sleep disorders and drug abuse. Research in adults indicates that sleep disorders, particularly insomnia, are related to stress and are commonly associated with substance abuse (cigarettes, alcohol, and illicit drugs), which, in turn, can affect sleep architecture by altering night-time awakenings and deeper sleep. Furthermore, the association between substance abuse and sleep disorders appears to be synchronous, with sleep problems increasing the risk of developing substance use disorders, and acute and chronic substance use potentially leading to sleep disorders [30-35]. Several studies pay particular attention to differences in risk factors, such as weight gain, dyslipidaemia, and substance abuse, between shift/night workers and day workers, which may contribute to the onset of various diseases [35-39]. Among these risk factors, alcohol consumption seems to be positively related to shift work activity, and it also appears that shift workers are likely to be binge-drinkers [40-42]. However, some studies have revealed no difference in alcohol consumption patterns between night/shift workers and daily workers $[43,44]$.

Alcohol, especially through its metabolites including acetaldehyde, is known to be a central nervous system depressant, with multiple effects including sedative effects, memory and learning deficits, and sleep-wake cycle disturbances [45,46]. Low doses of alcohol promote sleep induction, whereas, when its consumption becomes excessive, it reduces sleep quality [47]. In addition, large amounts of alcohol are associated with an increase in sleep latency, total sleep time and affect REM (rapid eye movement) sleep [48,49].

Based on the above premises, the purpose of this study was to firstly assess the association between night work and alcohol consumption and secondly the effect of alcohol on normal sleep, and the response to its use by people with insomnia disorder. Although this research had a limited sample size, it may make a further contribution to the investigation of the negative effects of night work as a possible risk factor for undesirable health effects and substance abuse.

\section{Materials and Methods}

\subsection{Design}

Data were collected from a private practice of Occupational Medicine in Palermo, Italy. This cross-sectional study was conducted from June 2020 to May 2021.

Subjects of both sexes were enrolled, aged between 24 and 67 years, and with a work history of at least 2 years.

Excluded from the study were all those who, at the time of the medical examination, presented sleep disorders, anxiety and depression or other psychiatric disorders treated with drugs; those with a BMI greater than or equal to 32; those with dysmetabolic diseases 
such as diabetes, hyperinsulinemia, hypercholesterolemia and hypertriglyceridemia under pharmacological treatment; those with current or previous oncological diseases; and those undergoing immunosuppressive or corticosteroid treatment. In addition, subjects who had been symptomatically infected with COVID-19 in the last six months were excluded from the study. These exclusion criteria were considered on the basis of the influence that both drug therapies and particular living conditions might have on sleep quality.

Specifically, the population consisted of $600(100 \%)$ workers belonging to a different type of daily or night work activity (security guard, mail sorter, production worker, parcel sorter) invited to participate in this study by their management. Among them $10 \%(n=60)$ refused to participate, the study initially recruited 540 (90\%) workers. All participants were informed about the purpose of the study and signed informed consent before participating. Respondents were asked not to mention their name or the name of their organization in the questionnaire to ensure privacy and anonymity.

At the first visit, all workers were questioned about their medical history, which included a differential diagnosis of sleep disorders, alcohol, or drug abuse, and underwent a physical examination (blood pressure measurements and electrocardiogram acquired by instrumental assessment from all patients).

At the end of the medical evaluation, a further 5\% (30) were excluded from the study because they were undergoing anxiolytic or antidepressant therapy at the time of the research. Finally, subjects with a body mass index greater than 32 with obvious dysmetabolic diseases or undergoing major therapies with antineoplastic drugs, immunosuppressants or corticosteroids or people who had contracted COVID symptomatically, requiring hospitalization were not included $12 \%$ (72).

We also randomly excluded an additional 18 males and 28 females to obtain the same number of day or night workers for each male and female sample. In the end, the study enrolled 392 adults, 222 males and 170 females (M/F ratio 1.3) (Table 1), divided into two different groups: 196 day workers (DW) and 196 night workers (NW). At the end of the patients' general anamnesis, all participants were invited to complete questionnaires regarding alcohol use, and insomnia disturbance (Figure 1).

Table 1. Demographic data and other baseline characteristics of patients included in the study. na: number; \%: percentage of patients; mean: mean value; SD: standard deviation; Min, Med and Max ranges, respectively.

\begin{tabular}{|c|c|c|c|c|c|c|c|}
\hline Male & & Percentage & Media & S.D & Min & Med & $\operatorname{Max}$ \\
\hline na & 222 & $56.6 \%$ & & & & & \\
\hline Age & & & 45.16 & 11.77 & 24 & 45 & 67 \\
\hline Height $(\mathrm{cm})$ & & & 1.74 & 0.079 & 1.6 & 1.75 & 1.91 \\
\hline Weight (kg) & & & 76.9 & 9.68 & 59 & 79 & 100 \\
\hline BMI & & & 25.25 & 3.02 & 18.11 & 25.29 & 31.9 \\
\hline \multicolumn{8}{|l|}{ Female } \\
\hline na & 170 & $44.4 \%$ & & & & & \\
\hline Age & & & 44.94 & 11.29 & 27 & 45 & 63 \\
\hline Height $(\mathrm{cm})$ & & & 1.68 & 0.0635 & 1.58 & 1.68 & 1.83 \\
\hline Weight (kg) & & & 67.6 & 7.65 & 50 & 69 & 82 \\
\hline BMI & & & 23.67 & 2.39 & 50 & 69 & 29.73 \\
\hline
\end{tabular}

All data were managed according to the Italian law for the protection of privacy (Decree n. 196, January 2003). A multidisciplinary team of health experts collected and analysed the data collected through the questionnaires administered regarding alcohol and sleep habits. 


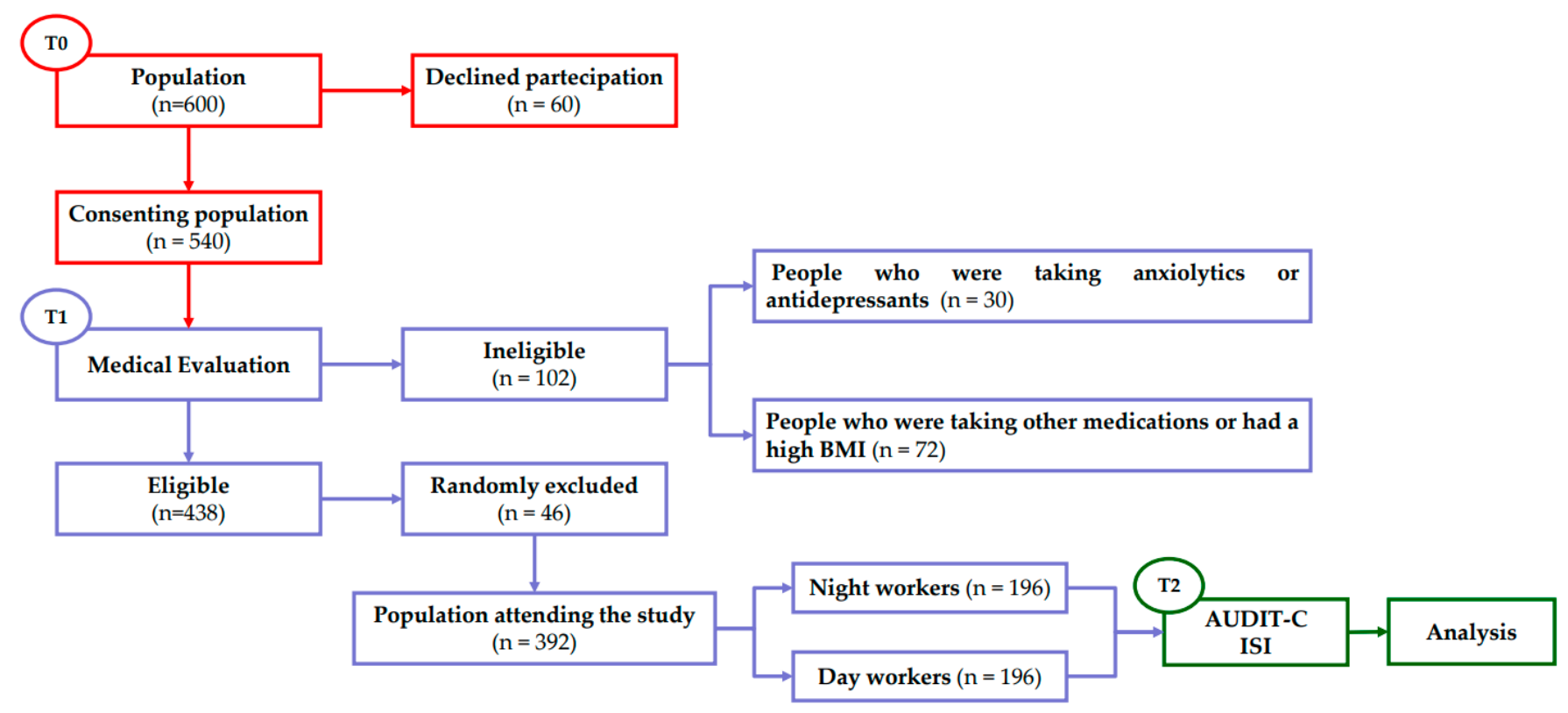

Figure 1. Flow chart of experimental procedures. T0: period in which the population was recruited; T1: period of general patient history useful for determining the final number of the population used in the study; T2: period in which the tests were administered and analysed.

\subsection{Assessment of Alcohol Consumption}

Alcohol use was assessed using a short form of the Alcohol Use Disorders Identification Test-Concise (AUDIT-C), a modified version of the 10-question Alcohol Use Disorders Identification Test (AUDIT) developed by the World Health Organization. This test is a brief self-reported alcohol screening test effective for assessing unhealthy alcohol use. This instrument is a 3-item survey with a total score ranging from 0 to 12 points. Each item has five response options rated from 0 points to 4 points. A score of 3 or more points on the AUDIT-C could indicate people who are at-risk drinkers or have alcohol use disorders. A score of 4 for men and 3 for women or more for each is considered predictive of potential alcohol abuse. Commonly, the likelihood of a person having an alcohol use disorder is directly proportional to the highest score on the test.

\subsection{Assessment of Insomnia Disorder}

The assessment of insomnia was conducted through the administration of the Insomnia Severity Index (ISI), a brief validated instrument that can assess the severity of both nocturnal and diurnal components of insomnia. This test is a self-report questionnaire that assesses the nature, severity, and impact of insomnia. The time period to which the test refers is the "last month" and the parameters assessed are severity of sleep onset time, sleep maintenance, morning awakenings, sleep dissatisfaction, interference of sleep difficulties with daytime functioning, visibility of sleep problems by others, and distress caused by sleep difficulties. This instrument consists of a 7-item survey ( 5 potential responses each) with a total score ranging from 0 (no problem) to 4 (very severe problem). The total score is interpreted as follows: no insomnia (0-7); subthreshold insomnia (8-14); moderate insomnia (15-21); and severe insomnia (22-28).

\subsection{Statistical Analysis}

Statistical analysis was performed using the Graph Pad Prism 8.01 statistical software package (San Diego, CA, USA). The data were tested for normal distribution using the D'Agostino \& Pearson omnibus normality test. Because of their normal distribution, statistical analysis was performed with a parametric test as reported. Differences in Alcohol Use Disorders Identification Test-Concise and Insomnia Severity Index scores between day and night workers were analyzed using Student's two-tailed $t$-test for unpaired data. 
For data on the correlation between AUDIT-C and ISI score, we performed a Pearson's correlation coefficient test. Simple linear regression analyses were generated as predictive models to assign the correlation found. To account for potential confounding factors, the variables gender and age were analysed by employing the General Linear ModelMultivariate Analysis of the Statistical Package for Social Sciences (International Business Machines Corp. IBM, Armonk, NY, USA, version 28). Data were reported as mean \pm SD or mean with $95 \%$ CI Statistical significance was set at $p<0.05$.

\section{Results}

\subsection{Alcohol Consumption}

Assessment of the frequency of alcohol consumption, the average amount of alcohol consumed, and the frequency of consumption of large amounts of alcohol during a short period of time (four to six units) was conducted using AUDIT-C. Initially, we estimated differences in risky drinking (drinking at levels that put a person at risk of medical or social problems) between day and night workers. Statistical analysis using a two-tailed Student's $t$-test for unpaired measures performed on the mean of the AUDIT-C score showed significant risky drinking behaviour in NWs $(\mathrm{t}=6.034, \mathrm{df}=390, p<0.001)$ compared to DWs (Figure 2).

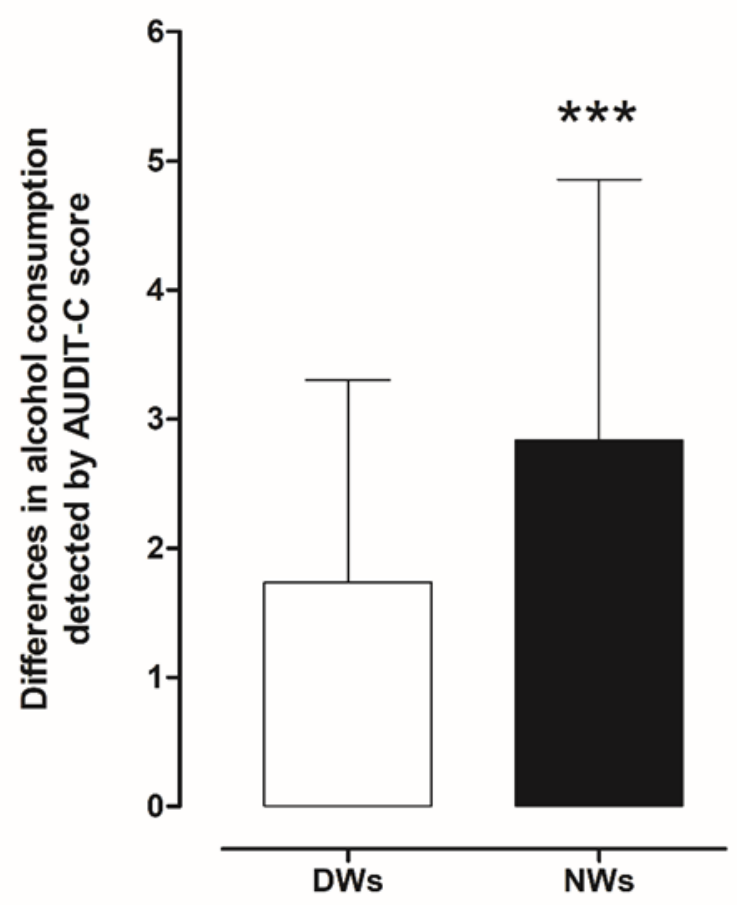

Figure 2. Comparison of differences in AUDIT-C scores between day and night workers. Each value represents the mean \pm S.D. of one hundred and six workers. ${ }^{* * *} p<0.001$ compared to daily workers. DWs, daily workers; NWs, night workers.

In more detail, a total of $162 \mathrm{NWs}$ (82.7\%; audit score (AS) 3.383, confidence interval (CI) 3.119-3.646) reported alcohol intake compared to 136 (69.4\%; AS 2.5, CI 2.284-2.716) of DWs; 129 NWs (65.8\%; AS 2.876, CI 2.638-3.144) reported occasional drinking, 18 (9.2\%; AS 4.8, CI 3.983-5.462) drank weekly and 16 (8.2\%; AS 6.1, CI 5.607-6.518) drank daily compared to DW 121(62.7\%; AS 2.2, CI 2.058-2.421), 12 (6.1\%; AS 4.4, CI 3.541-5.293), 3 (1.5\%; AS 5.3, CI 3.899-6.768).

In addition, according to the AUDIT-C criteria, we identified 66 workers (33.7\%; AS 5.0, CI 4.789-5.302) with harmful consumption in the NW group and 25 (12.8\%; AS 4.40, CI 4.009-4.871) in DW group. We also found 15 NWs (7.7\%; AS 5.7, CI 5.244-6.233) and 4 DWs 
(2\%; AS 5.5, CI 2.453-8.547) tended to consume greater amounts of alcohol per occasion (Figure 3) (Table 2).

\section{Daily workers}

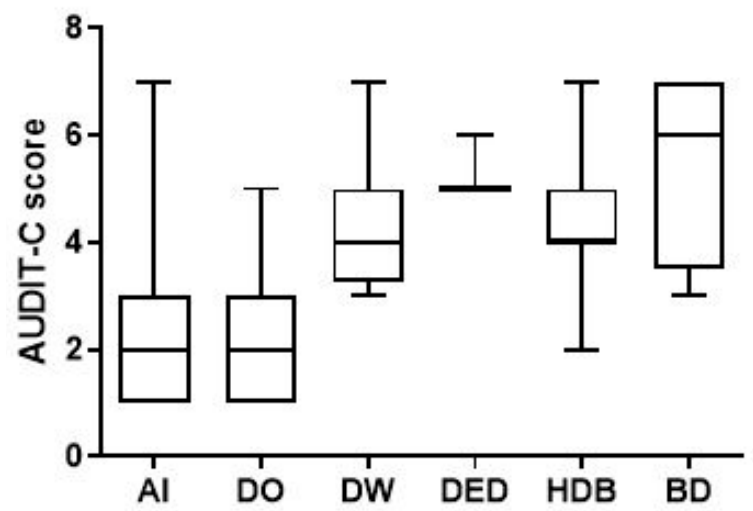

Night workers

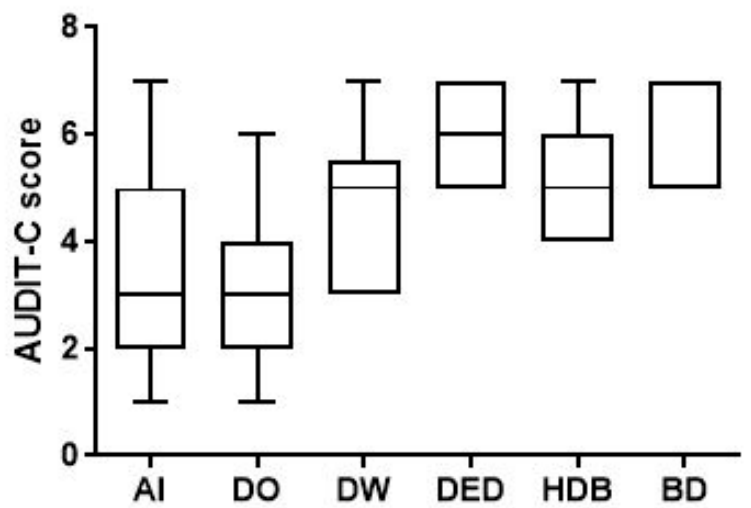

Figure 3. Data on alcohol consumption of the 196 day and night workers enrolled in the study. Above each bar is indicated the number of subjects belonging to the specific group. $\mathrm{AI}=$ alcohol intake; $\mathrm{DO}=$ drink occasionally; $\mathrm{DW}=\mathrm{drink}$ weekly; $\mathrm{DED}=$ drink every day; $\mathrm{HDB}=$ harmful drinking behaviour; $\mathrm{BD}=$ binge drinking.

Table 2. Data on alcohol consumption of the 196 day and night workers enrolled in the study. All data were calculated from the results obtained from AUDIT-C. $n^{\circ}=$ number; $\%=$ percentage.

\begin{tabular}{ccccc}
\hline & \multicolumn{2}{c}{ Daily Workers } & \multicolumn{2}{c}{ Night Workers } \\
\cline { 2 - 5 } & $\mathbf{n}^{\circ}$ & $\mathbf{\%}$ & $\mathbf{n}^{\circ}$ & $\mathbf{\%}$ \\
\hline Workers reporting alcohol intake & 196 & 100 & 196 & 100 \\
Workers who drink occasionally & 136 & 69.4 & 162 & 82.7 \\
Workers who drink weekly & 121 & 62.7 & 129 & 65.8 \\
Workers who drink every day & 12 & 6.1 & 18 & 9.2 \\
Workers with harmful drinking behaviour & 3 & 1.5 & 16 & 8.2 \\
Workers who engage in binge drinking & 25 & 12.8 & 66 & 33.7 \\
\hline
\end{tabular}

When AUDIT-C score was controlled for gender and age variable, the analysis indicated no significance impact of gender $(p=0.882)$ and age $(p=0.072)$.

\subsection{Insomnia Severity Index (ISI)}

The results obtained from the ISI scores were evaluated to investigate the presence of insomnia disorder among day and night workers. Statistical analysis using a two-tailed Student's $t$-test for unpaired data, performed on the mean of the total ISI score, showed a significant worsening of sleep quality in NWs $(t=3.0706, \mathrm{df}=390, p<0.002)$ compared to DWs (Figure 4).

To understand the degree of insomnia, we also divided the sample populations in relation to total score categories and analysed the difference between day and night workers.

As shown in in the picture (Figure 5), among the NWs participants in the study, a total of 151 (77\%; ISI 3.63, CI 3.266-3.992) reported no sleep problems, compared to $167 \mathrm{DWs}$ (85.2\%; ISI 2.63, CI 2.027-2.619); 29 (14.8\%; ISI 10.59, CI 9.90-11.27) had subthreshold insomnia, and 16 (8.2\%; ISI 17.06, CI 15.92-18.20) resulted in moderate clinical insomnia compared to DWs (7.7\%; ISI 10.47, CI 9.466-11.47), 12 (6.1\%; ISI 17.33, CI 15.82-18.75). We find only one ( $0.51 \%)$ DWs with severe clinical insomnia (Table 3$)$. 


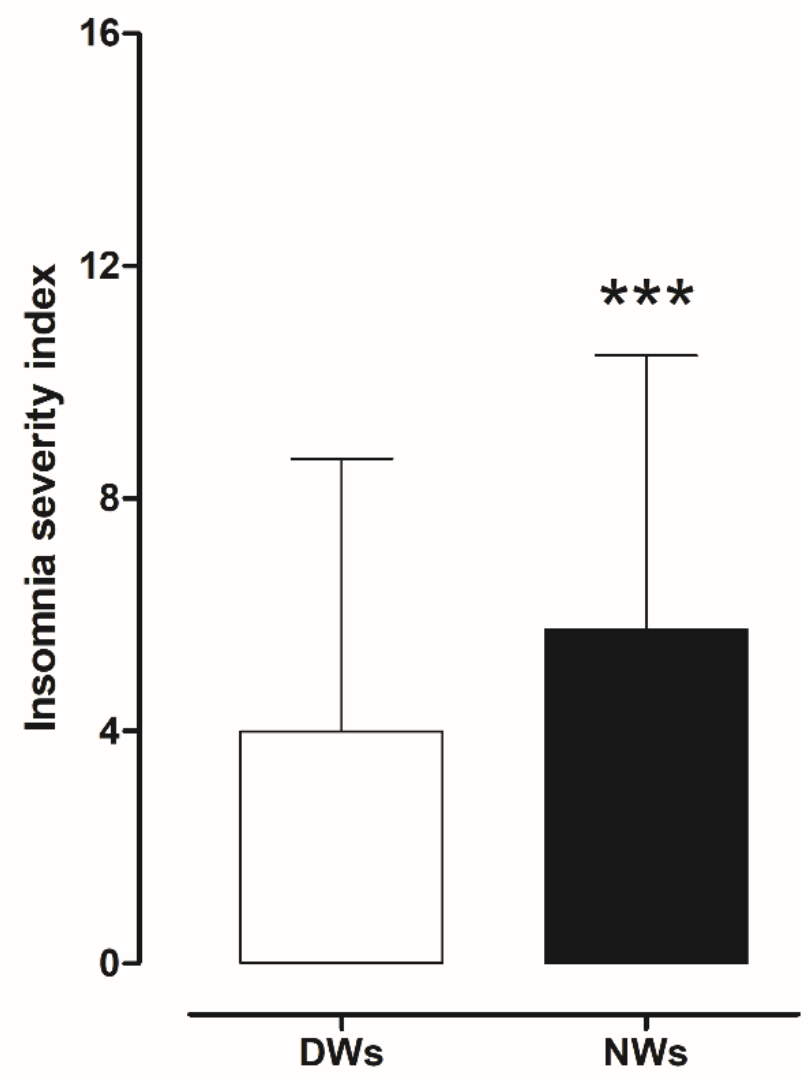

Figure 4. Differences in insomnia severity index score between day and night workers. Each value represents the mean \pm S.D. of one hundred and six workers. ${ }^{* * *} p<0.001$ compared to daily workers. DWs, daily workers; NWs, night workers.
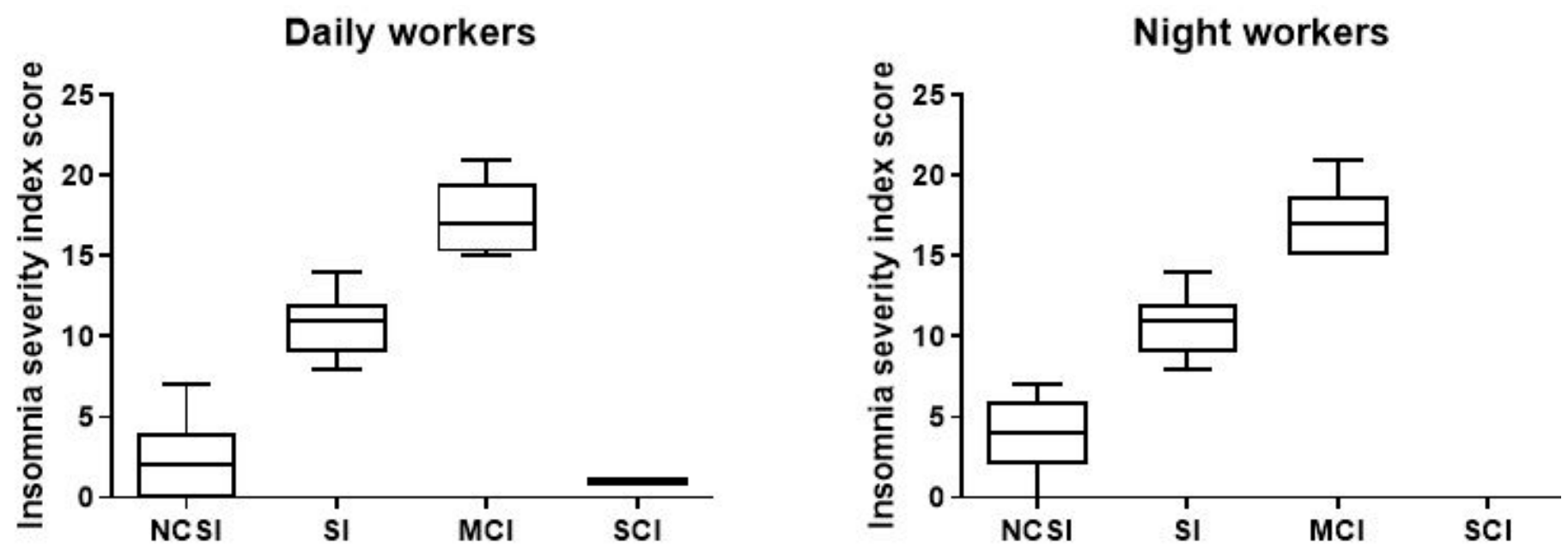

Figure 5. Data on sleep problems of the 196 day and night workers enrolled in the study. Above each bar is indicated the number of subjects belonging to the specific group. NCSI = no clinical significant insomnia; problems; SI = subthreshold insomnia; $\mathrm{MCI}$ = clinal insomnina; $\mathrm{SCI}$ = severe clinical insomnia. 
Table 3. Data on sleep problems of the 196 day and night workers enrolled in the study. All data were calculated from the results obtained from the Insomnia Severity Index score. $\mathrm{n}^{\circ}=$ number; $\%=$ percentage.

\begin{tabular}{ccccc}
\hline & \multicolumn{2}{c}{ Daily Workers } & \multicolumn{2}{c}{ Night Workers } \\
\cline { 2 - 5 } & $\mathbf{n}^{\circ}$ & $\mathbf{\%}$ & $\mathbf{n}^{\circ}$ & $\mathbf{\%}$ \\
\hline No clinically significant insomnia & 196 & 100 & 196 & 100 \\
Subthreshold insomnia & 167 & 85.2 & 151 & 77 \\
Moderate clinical insomnia & 15 & 7.7 & 29 & 14.8 \\
Severe clinical insomnia & 12 & 6.1 & 16 & 8.2 \\
\hline
\end{tabular}

When ISI score was controlled for gender variable, the analysis indicated no significance impact of gender $(p=0.661)$ and age (0.083).

\subsection{Alcohol Consumption and Insomnia Disorder}

Alcohol consumption and insomnia severity problems were assessed to evaluate a presumed influence of alcohol use with the onset of sleep disorders. For this purpose, Pearson's correlation coefficients between AUDIT-C score and ISI score were performed. A significant positive correlation was found between sleep problems and alcohol use in NWs $(\mathrm{r}=0.5781$, CI 0.4766-0.6645, $p<0.0001)$ (Figure 6) and DWs $(\mathrm{r}=0.5702, \mathrm{CI} 0.4674-0.6578$, $p<0.0001$ ) (Figure 7).

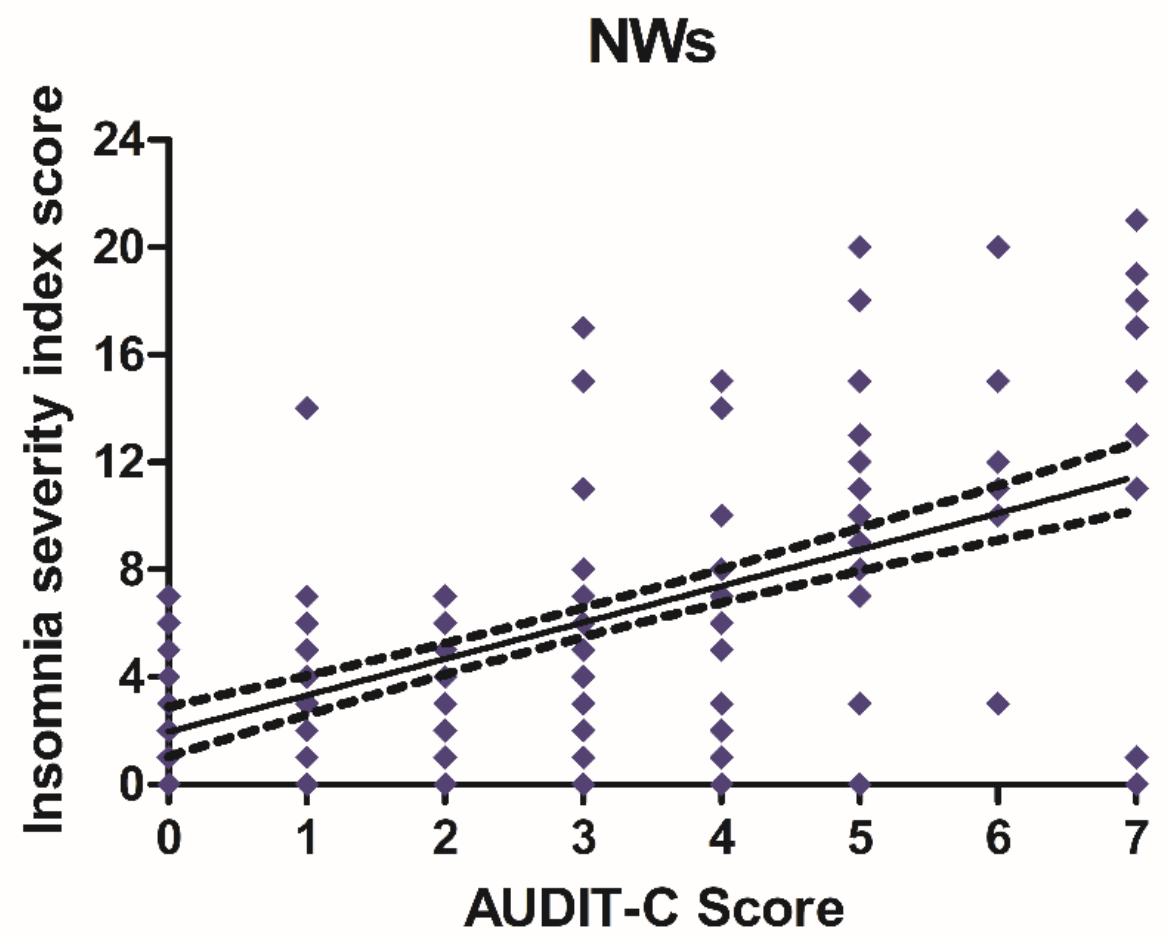

Figure 6. Correlation between AUDIT-C and ISI score in night workers. Each value represents the mean \pm S.D. of one hundred and ninety-six workers. DWs, daily workers; NWs, night workers. 


\section{DWs}

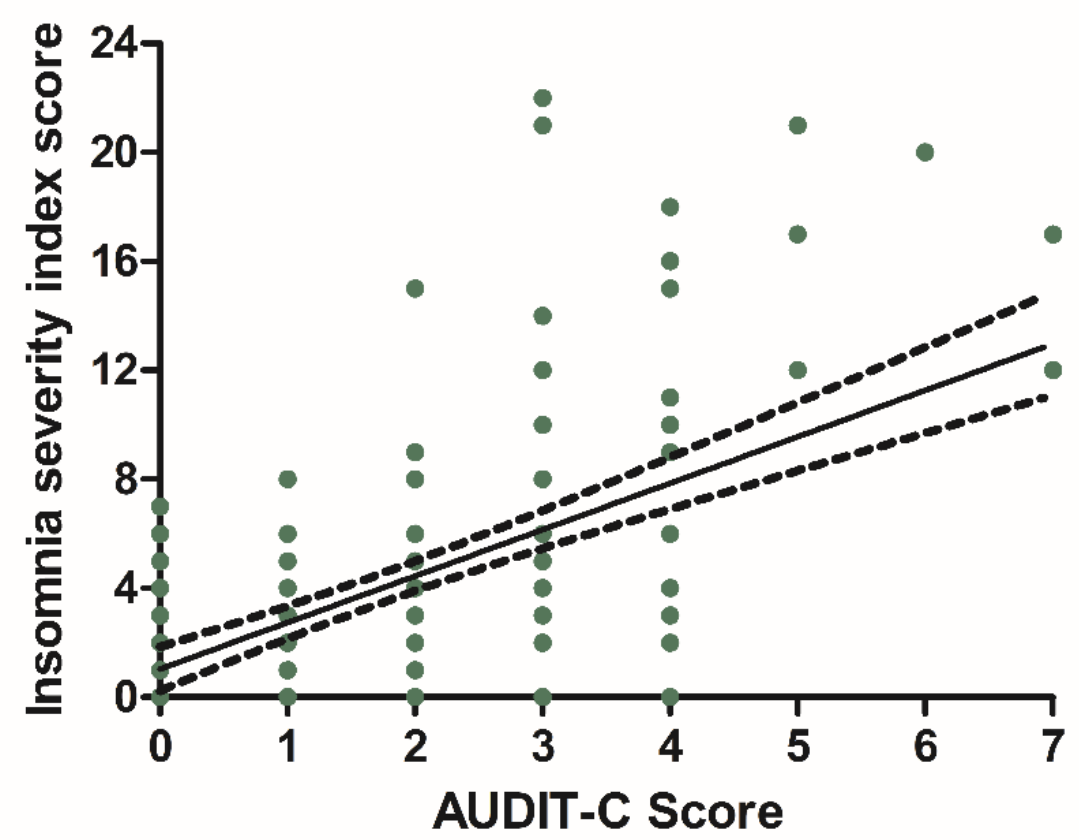

Figure 7. Correlation between AUDIT-C and ISI score in night workers. Each value represents the mean \pm S.D. one hundred and ninety-six workers. DWs, daily workers; NWs, night workers.

\section{Discussion}

The present research sought to examine differences in alcohol consumption and insomnia disorder among work groups with different work schedules. In addition, we investigated the links between alcohol consumption and insomnia. Using a questionnaire method to estimate alcohol consumption and risk behaviours [50], we found that, among daily workers, $22.4 \%$ had alcohol-related problems and that working primarily at night negatively influenced the occurrence of alcohol-related problems, resulting in 58.8\% of subjects having alcohol-related problems. Specifically, we found that, among people who work primarily at night, there were $33.7 \%$ of workers who engaged in harmful drinking behaviour, and $7.7 \%$ reported binge-drinking in the past year.

The results of this study are in agreement with some research showing that night workers are more likely to consume alcohol than day workers, often in a pattern of binge drinking $[35,36]$. These differences are likely due to the working conditions night workers are subjected to, which make them particularly vulnerable to stress. It is well established that particularly dangerous and demanding work, especially when performed at night, is a major stressor on the body and can affect the worker's overall health and well-being $[26,51,52]$. It is also important to remember that, at a biological level, the interruption and reversal of the sleep/wake cycle, together with the modified activity/rest pattern, can generate particularly stressful living conditions, making the night worker more vulnerable to stress-related disorders [53-57].

Stress, generally defined as any stimulus that disturbs the body's homeostasis, is an important predisposing factor to uncontrolled alcohol consumption [58,59]. On the other hand, the intake of alcohol is often related to its ability to alleviate a particular state of functional discomfort that leads the subject to constantly take the substance up to dependence $[60,61]$. The mechanisms that correlate stress with alcohol intake can be traced to their different modulation of the hypothalamic-pituitary-adrenal (HIP) axis [62,63]. Under stressful conditions, cortical and subcortical centers activate the hypothalamic paraventricular nucleus, promoting the secretion of corticotropin-releasing hormone (CRH) which, in 
turn, stimulates the release of adrenocorticotropic hormone (ACTH) by the adenohypophysis, causing the secretion of cortisol from the adrenal glands [64,65]. CRH is also capable of promoting increased levels of catecholamines (noradrenaline and dopamine) in certain extra-hypothalamic regions such as the amygdala and prefrontal cortex. This increase, along with that of glucocorticoids, is necessary for our brain both to understand the rewarding or aversive value of a substance and to learn the potential of its reinforcement, such as the learning associated with alcohol intake as a stress management mechanism [66-69].

Alcohol intake is able to modulate the same circuits that underlie the adaptive response to stress [70,71]. It has been shown that, after acute exposure to stress or moderate doses of alcohol, dopaminergic and hypothalamic circuits recover their normal basal tone allowing a normal response to novel stimuli [72]. In contrast, under conditions of intense stress or when high doses of alcohol are consumed, systems undergo a set of functional adaptations of reward and neuroendocrine regulatory circuits $[73,74]$ that may mark the pathophysiological change underlying the transition from controlled seeking to compulsive drinking $[75,76]$. Furthermore, binge drinking is able to generate tolerance to both stress and alcohol intake $[71,77,78]$.

The above can partly explain the results obtained in our research. Night workers, being subjected to particularly stressful working conditions [79,80], are more likely to consume high amounts of alcohol, probably implementing a coping strategy with respect to the stress they are subjected to on a daily basis during working hours. Moreover, the higher number of binge-drinkers is probably due to a greater sensitivity of some individuals to stress, which makes them more anxious and emotionally unstable and promotes the consumption of large amounts of alcohol in order to extinguish the unpleasant feeling of unbearable stress.

The amount of alcohol consumed by the workers in the study was well correlated with the analysis of of insomnia disorder. Specifically, the results obtained from the insomnia severity index questionnaire showed that there was a higher percentage of night workers $(23 \%)$ with insomnia than day workers $(14.31 \%)$. Several studies have shown that there is a bidirectional relationship between alcohol consumption and sleep problems. Specifically, insomnia predispose the subject to the abuse of various substances and, conversely, both acute and chronic consumption of these substances increases sleep disorders [81-84]. Among substances of abuse, alcohol seems to play a crucial role in the genesis of these disorders $[85,86]$.

A number of studies aimed at understanding the mechanisms underlying workers' health risks show that the behavioural strategies used to cope with sleep disturbances have a negative impact on their psychophysical integrity. Since workers have to sleep at different times than usual, they use different strategies to induce and improve sleep quality, including alcohol consumption [87-90].

This molecule has sedative properties and reduces the time needed to fall asleep [91]. However, the prolonged use of alcohol, especially in high concentrations, alters the quality of sleep, both prolonging the time needed to fall asleep and fragmenting the duration of sleep [92]. Finally, it is important to remember that the negative effects of alcohol, especially above recommended limits, are linked to several systemic diseases. Therefore, although perceived as a useful tool for those with sleep disorders, it can be seen as a tool that can promote the disorder itself, further increasing the risk to the health and safety of those who sleep.

The influence of alcohol on sleep architecture is partly attributable to its ability to modulate the activity of several chemicals responsible for nerve transmission. Alcohol acts in a dose-dependent manner by interfering with the action of gamma-aminobutyric acid (GABA) and glutamate, both of which play important roles in the regulation of sleep-wake rhythms [93,94]. Particularly, at low doses, alcohol facilitates the binding of GABA to its receptor site and exerts an antagonistic action on glutamate receptors, promoting an increase in the inhibitory signal and a reduction in the excitatory signal [95] in several brain areas involved in sleep regulation, such as the reticular portion of the brainstem, the 
thalamus, the hypothalamus, and the basal forebrain [96-98]. This alcohol-mediated action may partly explain the motivation of night workers to consume alcohol as a strategy to aid the falling asleep process. This pattern of consumption could also favour the establishment of risky behavioural patterns, which would lead the night worker to consume alcohol in such a way (binge drinking) and with such a frequency as to facilitate the onset of problems related to the use of the substance, as also demonstrated by the results of our research.

The percentage of subjects with alcohol-related problems among night workers compared with day workers may partially explain the high incidence of insomnia disorder found in this group. On the other hand, it has been reported that alcohol, taken in high concentrations and for fairly long periods of time, is able to modify sleep architecture and promote the onset of sleep disorders [86,99-101]. It has also been shown that the rate of sleep disturbance is significantly higher in individuals diagnosed with alcohol dependence than in the general population [102-104].

\section{Conclusions}

Although this study does not contain a very large sample, it provides further awareness of the importance of the negative impact of alcohol consumption on sleep quality in night workers.

A full understanding of the correlation between alcohol use and insomnia may provide a valuable and effective tool for assessing whether work performance is impaired.

Preventive action through accurate worker history, including the administration of questionnaires to detect the presence of alcohol or sleep disorders, would help both the health of the worker and the increased safety of the worker and those working with them.

Further research aimed at understanding the complexity of the relationship between night work, alcohol use and sleep disorders is timely and important. Alcohol use and the genesis of sleep disturbances can exert a strong negative pressure on already vulnerable physiological systems, leading to the onset of various illnesses and, although less important, decreased work performance.

Author Contributions: Conceptualization and Management, F.P. and E.C. have formulated evolution of overarching research goals and aims, coordinated the research activity planning and execution, and acquired the financial support project leading to this publication. Investigation, D.M., C.L., V.R., F.M. and D.V.; these authors have carried out research and investigation activity, specifically performing the experiments, or data/evidence collection. Formal analysis: F.P., L.C. and V.C.; they have provided statistical, mathematical, computational, or other formal techniques to analyze or synthesize study data. Furthermore, F.P. was responsible for the writing of the original draft, and has prepared, created and presented the work. All authors have read and agreed to the published version of the manuscript.

Funding: This research was supported by a grant from Funding for Basic Activities Related to Research (FFABR), Italian National Agency for the Evaluation of Universities and Research Institutes.

Institutional Review Board Statement: Ethical review and approval were waived for this study, as the study, being non-invasive and involving simple data collection, was conducted on patients seen in a private practice. At the same time, it should be emphasized that, although there was no need for an evaluation by the ethics committee, for the reasons outlined above, the study was conducted considering the guidelines of the Declaration of Helsinki.

Informed Consent Statement: Informed consent was obtained from all subjects involved in the study.

Data Availability Statement: The data is not publicly available due to privacy restrictions.

Conflicts of Interest: The authors declare no conflict of interest.

\section{References}

1. Cipriani, G.; Lucetti, C.; Danti, S.; Nuti, A. Sleep disorders and dementia. Psychogeriatrics 2015, 15, 65-74. [CrossRef] [PubMed]

2. Murphy, M.J.; Peterson, M.J. Sleep disorders in depression. Sleep Med. Clin. 2015, 10, 17-23. [CrossRef]

3. Robinson-Shelton, A.; Malow, B.A. Sleep disturbances in neurodevelopmental disorders. Curr. Psychiatry Rep. 2016, $18,6$. [CrossRef] 
4. Angarita, G.A.; Emadi, N.; Hodges, S.; Morgan, P.T. Sleep abnormalities associated with alcohol, cannabis, cocaine, and opioid use: A comprehensive review. Addict. Sci. Clin. Pract. 2016, 11, 9. [CrossRef] [PubMed]

5. Ramaci, T.; Barattucci, M.; Vella, F.; Senia, P.; Cannizzaro, E.; Scorciapino, A.; Ledda, C.; De Giorgio, A.; Rapisarda, V. Straining at Work and Its Relationship with Personality Profiles and Individual Consequences in Healthcare Workers (HCWs). Int. J. Environ. Res. Public Health 2020, 17, 610. [CrossRef]

6. Cannizzaro, E.; Plescia, F.; Cirrincione, L.; Lo Pinto, E.; Plescia, F. Sport for job differences in cortisol levels in a water polo team at different times of workout. EuroMediterranean Biomed. J. 2018, 13, 181-184.

7. Ting, L.; Malhotra, A. Sleep disorders: An overview. Prim. Care Clin. Off. Pr. 2005, 32, 305-318. [CrossRef]

8. Goldstein, I.B.; Ancoli-Israel, S.; Shapiro, D. Relationship between daytime sleepiness and blood pressure in healthy older adults. Am. J. Hypertens. 2004, 17, 787-792. [CrossRef]

9. Alvarez, G.G.; Ayas, N.T. The impact of daily sleep duration on health: A review of the literature. Prog. Cardiovasc. Nurs. 2004, 19, 56-59. [CrossRef] [PubMed]

10. Hanly, P. Sleep apnea and daytime sleepiness in end-stage renal disease. Semin. Dial. 2004, 17, 109-114. [CrossRef] [PubMed]

11. Hilton, M.F.; Chappell, M.J.; Bartlett, W.A.; Malhotra, A.; Beattie, J.M.; Cayton, R.M. Sleep apnea/hypopnea syndrome depresses vagal tone on awakening independently of sympathetic activation. Eur. Respir J. 2001, 17, 1258-1266. [CrossRef] [PubMed]

12. Hepburn, M.; Bollu, P.C.; French, B.; Sahota, P. Sleep Medicine: Stroke and Sleep. Mo. Med. 2018, 115, 527-532.

13. Duce, B.; Kulkas, A.; Langton, C.; Töyräs, J.; Hukins, C. The prevalence of REM-related obstructive sleep apnoea is reduced by the AASM 2012 hypopnoea criteria. Sleep Breath 2018, 22, 57-64. [CrossRef] [PubMed]

14. Li, J.; Covassin, N.; Bock, J.M.; Mohamed, E.A.; Pappoppula, L.P.; Shafi, C.; Lopez-Jimenez, F.; Somers, V.K. Excessive Daytime Sleepiness and Cardiovascular Mortality in US Adults: A NHANES 2005-2008 Follow-Up Study. Nat. Sci. Sleep 2021, 13, 1049-1059. [CrossRef] [PubMed]

15. Olszowka, M.; Held, C.; Hadziosmanovic, N.; Denchev, S.; Manolis, A.; Wallentin, L.; White, H.D.; Stewart, R.A.H.; Hagström, E.; STABILITY Investigators. Excessive daytime sleepiness, morning tiredness and major adverse cardiovascular events in patients with chronic coronary syndrome. J. Intern. Med. 2021, 290, 392-403. [CrossRef] [PubMed]

16. Taylor, D.J.; Mallory, L.J.; Lichstein, K.L.; Durrence, H.H.; Riedel, B.W.; Bush, A.J. Comorbidity of chronic insomnia with medical problems. Sleep 2007, 30, 213-218. [CrossRef]

17. Foley, D.; Ancoli-Israel, S.; Britz, P.; Walsh, J. Sleep disorders and chronic disease in older adults: Results from the 2003 National Sleep Foundation Sleep in America Survey. J. Psychosom. Res. 2004, 56, 497-502. [CrossRef] [PubMed]

18. Ballacchino, A.; Salvago, P.; Cannizzaro, E.; Costanzo, R.; Di Marzo, M.; Ferrara, S.; Mattina, E.L.; Messina, G.; Mucia, M.; Mule, L.; et al. Association between sleep-disordered breathing and hearing disorders: Clinical observation in Sicilian patients. Acta Med. Mediterr. 2015, 31, 607-614.

19. Pace, A.; Iannella, G.; Rossetti, V.; Visconti, I.C.; Gulotta, G.; Cavaliere, C.; De Vito, A.; Maniaci, A.; Cocuzza, S.; Magliulo, G.; et al. Diagnosis of Obstructive Sleep Apnea in Patients with Allergic and Non-Allergic Rhinitis. Medicina 2020, 56, 454. [CrossRef] [PubMed]

20. Liu, J.; Wu, Y.; Wu, P.; Xu, Z.; Ni, X. Analysis of the impact of allergic rhinitis on the children with sleep disordered breathing. Int. J. Pediatr. Otorhinolaryngol. 2020, 138, 110380. [CrossRef] [PubMed]

21. Costantino, C.; Cannizzaro, E.; Alba, D.; Conforto, A.; Cimino, L.; Mazzucco, W. Sars-CoV-2 pandemic in the mediterranean area: Epidemiology and perspectives. EuroMediterranean Biomed. J. 2020, 15, 102-106.

22. Cirrincione, L.; Rapisarda, V.; Mazzucco, W.; Provenzano, R.; Cannizzaro, E. Sars-CoV-2 and the Risk Assessment Document in Italian Work; Specific or Generic Risk Even If Aggravated? Int. J. Environ. Res. Public Health 2021, 18, 3729. [CrossRef] [PubMed]

23. Cannizzaro, E.; Cannizzaro, C.; Martorana, D.; Moscadini, S.; Coco, D.L. Effects of shift work on cardiovascular activity, serum cortisol and white blood cell count in a group of Italian fishermen. EuroMediterranean Biomed. J. 2012, 2012, $109-113$.

24. C171-Convention on Night Work, $n$. 171; International Labour Organisation (ILO): Geneva, Switzerland, 1990.

25. Rajaratnam, S.M.; Arendt, J. Health in a 24-h society. Lancet 2001, 358, 999-1005. [CrossRef]

26. Cannizzaro, E.; Cirrincione, L.; Mazzucco, W.; Scorciapino, A.; Catalano, C.; Ramaci, T.; Ledda, C.; Plescia, F. Night-Time Shift Work and Related Stress Responses: A study of security guards. Int. J. Environ. Res. Public Health 2020, 17, 562. [CrossRef] [PubMed]

27. Rapisarda, V.; Cannizzaro, E.; Barchitta, M.; Vitale, E.; Cinà, D.; Minciullo, F.; Matera, S.; Bracci, M.; Agodi, A.; Ledda, C. A Combined Multidisciplinary Intervention for Health Promotion in the Workplace: A Pilot Study. J. Clin. Med. 2021, $10,1512$. [CrossRef] [PubMed]

28. Maggiulli, R.; Giancani, A.; Fabozzi, G.; Dovere, L.; Tacconi, L.; Amendola, M.G.; Cimadomo, D.; Ubaldi, F.M.; Rienzi, L. Assessment and management of the risk of SARS-CoV-2 infection in an IVF laboratory. Reprod. Biomed. Online 2020, 41, 385-394. [CrossRef] [PubMed]

29. Soleo, L.; Cannizzaro, E.; Lovreglio, P.; Basso, A.; D’Errico, M.N.; Pira, E. Protocols for the health surveillance [Protocolli per la sorveglianza sanitaria dei lavoratori della pesca]. G. Ital. Med. Lav. Ergon. 2013, 35, 222-226.

30. Plescia, F.; Brancato, A.; Venniro, M.; Maniaci, G.; Cannizzaro, E.; Sutera, F.M.; Caro, V.D.; Giannola, L.I.; Cannizzaro, C. Acetaldehyde self-administration by a two-bottle choice paradigm: Consequences on emotional reactivity, spatial learning, and memory. Alcohol 2015, 49, 139-148. [CrossRef] 
31. Plescia, F.; Cannizzaro, E.; Brancato, A.; Martines, F.; Di Naro, A.; Mucia, M.; Plescia, F.; Vita, C.; Salvago, P.; Mulè, A.; et al. Acetaldehyde effects in the brain. Acta Med. Mediterr. 2015, 31, 813-817.

32. Roehrs, T.A.; Roth, T. Sleep Disturbance in Substance Use Disorders. Psychiatr. Clin. N. Am. 2015, 38, 793-803. [CrossRef] [PubMed]

33. NIDA. Links between Sleep and Substance Use Disorders. National Institute on Drug Abuse Website. Available online: https:/ / www.drugabuse.gov/about-nida/noras-blog/2020/03/connections-between-sleep-substance-use-disorders (accessed on 5 June 2021).

34. Chakravorty, S.; Vandrey, R.G.; He, S.; Stein, M.D. Sleep management among patients with substance use disorders. Med. Clin. N. Am. 2018, 102, 733-743. [CrossRef] [PubMed]

35. Morikawa, Y.; Nakagawa, H.; Miura, K.; Soyama, Y.; Ishizaki, M.; Kido, T.; Naruse, Y.; Suwazono, Y.; Nogawa, K. Effect of shift work on body mass index and metabolic parameters. Scand. J. Work Environ. Health 2007, 33, 45-50. [CrossRef] [PubMed]

36. Pietroiusti, A.; Neri, A.; Somma, G.; Coppeta, L.; Iavicoli, I.; Bergamaschi, A.; Magrini, A. Incidence of metabolic syndrome among night shift health workers. Occup. Environ. Med. 2010, 67, 54-57. [CrossRef] [PubMed]

37. Biggi, N.; Consonni, D.; Galluzzo, V.; Sogliani, M.; Costa, G. Metabolic syndrome in permanent night workers. Chronobiol. Int. 2008, 25, 443-454. [CrossRef]

38. Gibson, M. A systematic review of the relationship between night shift work and oxidative stress. Chronobiol. Int. 2021, 14, 1-14. [CrossRef]

39. Pearson, T.A.; Blair, S.N.; Daniels, S.R.; Eckel, R.H.; Fair, J.M.; Fortmann, S.P.; Franklin, B.A.; Goldstein, L.B.; Greenland, P.; Grundy, S.M.; et al. AHA guidelines for primary prevention of cardiovascular disease and stroke: 2002 update: Consensus group guidance on comprehensive risk reduction for adult patients without coronary artery disease or other atherosclerotic vascular disease. Circulation 2002, 2002, 388-391. [CrossRef] [PubMed]

40. Dorrian, J.; Heath, G.; Sargent, C.; Banks, S.; Coates, A. Alcohol use in shift workers. Accid. Anal. Prev. 2017, 99, 395-400. [CrossRef] [PubMed]

41. Dorrian, J.; Coates, A.; Heath, G.; Banks, S. Patterns of alcohol consumption and sleep in shiftworkers. In Sleep Modulation by Obesity, Diabetes, Age, and Diet; Watson, R.R., Ed.; Academic Press: London, UK, 2014; pp. 353-361.

42. Buchvold, H.V.; Pallesen, S.; Øyane, N.M.; Bjorvatn, B. Associations between night work and BMI, alcohol, smoking, caffeine and exercise-A cross-sectional study. BMC Public Health 2015, 15, 1112. [CrossRef] [PubMed]

43. Flo, E.; Pallesen, S.; Magerøy, N.; Moen, B.E.; Grønli, J.; Hilde Nordhus, I.; Bjorvatn, B. Shift Work Disorder in Nurses-Assessment, Prevalence and Related Health Problems. PLoS ONE 2012, 7, e33981. [CrossRef] [PubMed]

44. Hermansson, U.; Knutsson, A.; Brandt, L.; Huss, A.; Rönnberg, S.; Helander, A. Screening for high risk and high alcohol consumption in day and shift workers using AUDIT and CDT. Occup. Med. 2003, 53, 518-526. [CrossRef] [PubMed]

45. DSM-5. Diagnostic and Statistical Manual of Mental Disorders, 5th ed.; Arlington, V.A., Ed.; American Psychiatric Publishing: Washington, DC, USA, 2013.

46. Chakravorty, S.; Chaudhary, N.S.; Brower, K.J. Alcohol dependence and its relationship to insomnia and other sleep disorders. Alcohol Clin. Exp. Res. 2016, 40, 2271-2282. [CrossRef]

47. Vitiello, M.V. Sleep, alcohol, and alcohol abuse. Addict. Biol. 1997, 2, 151-158. [CrossRef]

48. Laniepce, A.; Cabé, N.; André, C.; Bertran, F.; Boudehent, C.; Lahbairi, N.; Maillard, A.; Mary, A.; Segobin, S.; Vabret, F.; et al. The effect of alcohol withdrawal syndrome severity on sleep, brain and cognition. Brain Commun. 2020, 2, fcaa123. [CrossRef] [PubMed]

49. Brower, K.J. Insomnia, alcoholism, and relapse. Sleep Med. Rev. 2003, 7, 523-539. [CrossRef]

50. Bazzo, S.; Battistella, G.; Riscica, P.; Moino, G.; Dal Pozzo, G.; Bottarel, M.; Geromel, M.; Czerwinsky, L. Reliability of an Italian self-report version of the AUDIT-C questionnaire used to estimate alcohol consumption by pregnant women in an obstetric setting. Riv. Psychiatr. 2015, 50, 89-94.

51. Hemiö, K.; Lindström, J.; Peltonen, M.; Härmä, M.; Viitasalo, K.; Puttonen, S. The association of work stress and night work with nutrient intake-A prospective cohort study. Scand. J. Work Environ. Health 2020, 46, 533-541. [CrossRef] [PubMed]

52. Boucsein, W.; Ottmann, W. Psychophysiological stress effects from the combination of night work and noise. Biol. Psychol. 1996, 42, 301-322. [CrossRef]

53. Lichtenstein, M.B.; Malkenes, M.; Sibbersen, C.; Hinze, C.J. Work dependence is associated with increased stress and reduced quality of life: Validation of the Bergen Work Dependence Scale in Danish. Scand. J. Psychol. 2019, 60, 145-151. [CrossRef]

54. Stanek, A.; Brożyna-Tkaczyk, K.; Myśliński, W. Oxidative Stress Markers among Obstructive Sleep Apnea Patients. Oxid. Med. Cell Longev. 2021, 2021, 9681595. [CrossRef]

55. Maniaci, A.; Iannella, G.; Cocuzza, S.; Vicini, C.; Magliulo, G.; Ferlito, S.; Cammaroto, G.; Meccariello, G.; De Vito, A.; Nicolai, A.; et al. Oxidative Stress and Inflammation Biomarker Expression in Obstructive Sleep Apnea Patients. J. Clin. Med. 2021, 10, 277. [CrossRef] [PubMed]

56. Richman, J.A.; Flaherty, J.A.; Rospenda, M. Perceived experiences of workplace harassment and alcohol problems among physicians: Expanding the stress/alienation paradigm. Addiction 1996, 91, 391-403. [CrossRef] [PubMed]

57. Costa, G. Shift work and health: Current problems and preventive actions. Saf. Health Work 2010, 1, 112-123. [CrossRef]

58. Cannizzaro, E.; Ramaci, T.; Cirrincione, L.; Plescia, F. Occupational stress, pathophysiological mechanisms and influence of environmental genetic factors. Int. J. Environ. Res. Public Health 2019, 16, 4031. [CrossRef] 
59. Powers, R.J.; Kutash, I.L. Stress and alcohol. Int. J. Addict. 1985, 20, 461-482. [CrossRef] [PubMed]

60. Kersey, K.; Lyons, A.C.; Hutton, F. Alcohol and drinking within the lives of midlife women: A meta-study systematic review. Int. J. Drug Policy 2021, 99, 103453. [CrossRef]

61. Sayette, M.A. Does drinking reduce stress? Alcohol Res. Health 1999, 23, 250-255. [PubMed]

62. Schepis, T.S.; Rao, U.; Yadav, H.; Adinoff, B. The limbic-hypothalamic-pituitary-adrenal axis and the development of alcohol use disorders in youth. Alcohol. Clin. Exp. Res. 2011, 35, 595-605. [CrossRef] [PubMed]

63. Majewska, M.D. HPA axis and stimulant dependence: An enigmatic relationship. Psychoneuroendocrinology 2002, 27, 5-12. [CrossRef]

64. Cannizzaro, C.; La Barbera, M.; Plescia, F.; Cacace, S.; Tringali, G. Ethanol modulates corticotropin-releasing hormone release from the rat hypothalamus: Does acetaldehyde play a role? Alcohol. Clin. Exp. Res. 2010, 34, 588-593. [CrossRef] [PubMed]

65. Arnsten, A.F. Stress signaling pathways impairing prefrontal cortex structure and function. Nat. Rev. Neurosci. 2009, 10, 410-422. [CrossRef]

66. Herman, J.P.; Ostrander, M.M.; Mueller, N.K.; Figueiredo, H. Limbic system mechanisms of stress regulation: Hypothalamicpituitary-adrenocortical axis. Adv. Neuro-Psychopharmacol. Biol. Psychiatry 2005, 29, 1201-1213. [CrossRef]

67. Roozendaal, B.; Quirarte, G.L.; McGaugh, J.L. Glucocorticoids interact with the basolateral amygdala $\beta$-adrenoceptorcAMP/cAMP/PKA receptor system in influencing memory consolidation. Eur. J. Neurosci. 2002, 15, 553-560. [CrossRef] [PubMed]

68. Belujon, P.; Grace, A.A. Regulation of dopamine system reactivity and its adaptive and pathological response to stress. Proc. R. Soc. Lond. B Biol. Sci. 2015, 282, 20142516.

69. Schwabe, L.; Dickinson, A.; Wolf, O.T. Stress, habits, and drug addiction: A psychoneuroendocrinological perspective. Exp. Clin. Psychopharmacol. 2011, 19, 53-63. [CrossRef] [PubMed]

70. Blaine, S.K.; Milivojevic, V.; Fox, H.; Sinha, R. Effects of alcohol on stress pathways: Impact on Craving and risk of relapse. Can. J. Psychiatry 2016, 61, 145-153. [CrossRef] [PubMed]

71. Allen, C.D.; Rivier, C.L.; Lee, S.Y. Adolescent alcohol exposure alters central brain circuits known to regulate the stress response. Neuroscience 2011, 182, 162-168. [CrossRef]

72. McEwen, B.S. Stress, adaptation, and disease: Allostasis and allostatic load. Ann. N. Y. Acad. Sci. 1998, 840, 33-44. [CrossRef] [PubMed]

73. Koob, G.F.; Le Moal, M. Plasticity of the reward neurocircuitry and the 'dark side' of drug addiction. Nat. Neurosci. 2005, 8, 1442-1444. [CrossRef] [PubMed]

74. Sinha, R. How does stress increase the risk of drug abuse and relapse? Psychopharmacology 2001, 158, 343-359. [CrossRef] [PubMed]

75. Sinha, R. Chronic stress, drug use, and vulnerability to addiction. Ann. N. Y. Acad. Sci. 2008, 1141, 105-130. [CrossRef]

76. Sinha, R. Risk factors for substance use, abuse and dependence: Stress. In Encyclopedia of Drugs, Alcohol, and Addictive Behaviors, 3rd ed.; Kranzler, H., Korsmeyer, P., Eds.; MacMillan Reference: New York, NY, USA, 2008.

77. Lovallo, W.R. Cortisol secretion patterns in addiction and the risk of addiction. Int. J. Psychophysiol. 2006, 59, 195-202. [CrossRef]

78. Heilig, M.; He, M.; Crabbe, J.C.; Becker, H.C. Acute abstinence, protracted abstinence, and negative affect in alcoholism: Are they related? Biol. Addict. 2010, 15, 169-184. [CrossRef] [PubMed]

79. Ferri, P.; Guadi, M.; Marcheselli, L.; Balduzzi, S.; Magnani, D.; Di Lorenzo, R. The impact of shift work on the psychological and physical health of nurses in a general hospital: A comparison between rotating night shifts and day shifts. Risk Manag. Healthc. Policy 2016, 9, 203-211. [CrossRef] [PubMed]

80. McVicar, A. Analysis of common antecedents of nurses' job stress and job satisfaction (2000-2013) using the demand- and resource-based stress model. J. Nurs. Manag. 2016, 24, E112-E136. [CrossRef] [PubMed]

81. Haario, P.; Rahkonen, O.; Laaksonen, M.; Lahelma, E.; Lallukka, T. Bidirectional associations between insomnia symptoms and unhealthy behaviors. J. Sleep Res. 2013, 22, 89-95. [CrossRef]

82. Roehrs, T.; Papineau, K.; Rosenthal, L.; Roth, T. Ethanol as a hypnotic in insomniacs: Self-administration and effects on sleep and mood. Neuropsychopharmacology 1999, 20, 279-286. [CrossRef]

83. Burke, C.K.; Peirce, J.M.; Kidorf, M.S.; Neubauer, D.; Punjabi, N.M.; Stoller, K.B.; Hursh, S.; Brooner, R.K. Sleep problems reported by patients entering treatment with opioid agonists. J. Subst. Abuse Treat. 2008, 35, 328-333. [CrossRef]

84. Johanson, C.E.; Roehrs, T.; Schuh, K.; Warbasse, L. The effects of cocaine on mood and sleep in cocaine-dependent males. Exp. Clin. Psychopharmacol. 1999, 7, 338-346. [CrossRef]

85. He, S.; Hasler, B.P.; Chakravorty, S. Alcohol and sleep problems. Curr. Opin. Psychol. 2019, 30, 117-122. [CrossRef] [PubMed]

86. Uchimura, N. [Sleep disorders related to alcohol dependence]. Seishin Shinkeigaku Zasshi. 2010, 112, 787-792. [PubMed]

87. Richardson, G.S.; Miner, J.D.; Czeisler, C.A. Impaired driving performance in shift workers: The role of the circadian system in a multifactorial model. Alcohol Drugs Driv. 1989, 5-6, 265-273.

88. Gold, D.R.; Rogacz, S.; Bock, N.; Tosteson, T.D.; Baum, T.M.; Speizer, F.E.; Czeisler, C.A. Rotating shift work, sleep, and sleep-related accidents in hospital nurses. Am. J. Public Health 1992, 82, 1011-1014. [CrossRef] [PubMed]

89. Knauth, P.; Hornberger, S. Preventive and compensatory measures for shift workers. Occup. Med. 2003, 53, 109-116. [CrossRef] [PubMed] 
90. Dorrian, J.; Paterson, J.; Dawson, D.; Pincombe, J.; Grech, C.; Rogers, A.E. Sleep, stress and compensatory behaviours in Australian nurses and midwives. Rev. Saude Publica 2011, 45, 922-930. [CrossRef] [PubMed]

91. Roehrs, T.; Roth, T. Sleep, drowsiness, and alcohol use. Alcohol Res. Health 2001, 25, 101-109. [PubMed]

92. Chung, Y.; Kim, H.; Koh, D.H.; Park, J.H.; Yoon, S. Relationship Between Shift Intensity and Insomnia Among Hospital Nurses in Korea: A Cross-sectional Study. J. Prev. Med. Public Health 2021, 54, 46-54. [CrossRef]

93. Koob, G.F. Drug addiction: The yin and yang of hedonic homeostasis. Neuron 1996, 16, 893-896. [CrossRef]

94. Jones, K.A.; Tamm, J.A.; Craig, D.A.; Yao, W.; Panic, R. Signal transduction by GABA(B) receptor heterodimers. Neuropsychopharmacology 2000, 23 (Suppl. 4), S41-S49. [CrossRef]

95. Krystal, J.H.; Staley, J.; Mason, G.; Petrakis, I.L.; Kaufman, J.; Harris, R.A.; Gelernter, J.; Lappalainen, J. Gamma-aminobutyric acid type A receptors and alcoholism: Intoxication, dependence, vulnerability, and treatment. Arch. Gen. Psychiatry 2006, 63, 957-968. [CrossRef]

96. Saper, C.B.; Scammell, T.E.; Lu, J. Hypothalamic regulation of sleep and circadian rhythms. Nature 2005, 437, 1257-1263. [CrossRef]

97. Brown, C.L.; Gibbons, L.E.; Kennison, R.F.; Robitaille, A.; Lindwall, M.; Mitchell, M.B.; Shirk, S.D.; Atri, A.; Cimino, C.R.; Benitez, R.; et al. Social activity and cognitive functioning over time: A coordinated analysis of four longitudinal studies. J. Aging Res. 2012, 2012, 287438. [CrossRef]

98. Gent, T.C.; Bandarabadi, M.; Herrera, C.G.; Adamantidis, A.R. Dual thalamic control of sleep and wakefulness. Nat. Neurosci. 2018, 21, 974-984. [CrossRef] [PubMed]

99. Banks, S.; Catcheside, P.; Lack, L.; Grunstein, R.R.; McEvoy, R.D. Low alcohol levels impair driving simulator performance and reduce perception of crash risk in partially sleep deprived subjects. Sleep 2004, 27, 1063-1067. [CrossRef] [PubMed]

100. Thakkar, M.M.; Sharma, R.; Sahota, P. Alcohol disrupts sleep homeostasis. Alcohol 2015, 49, 299-310. [CrossRef] [PubMed]

101. Arnedt, J.T.; Rohsenow, D.J.; Almeida, A.B.; Hunt, S.K.; Gokhale, M.; Gottlieb, D.J.; Howland, J. Sleep after alcohol intoxication in healthy, young adults: Effects of sex and family history of alcoholism. Alcohol Clin. Exp. Res. 2011, 35, 870-878. [CrossRef] [PubMed]

102. Caetano, R.; Clark, C.L.; Greenfield, T.K. Prevalence, trends, and incidence of alcohol withdrawal symptoms: Analysis of general population and clinical samples. Alcohol Health Res. World 1998, 22, 73-79. [PubMed]

103. Foster, J.H.; Marshall, E.J.; Peters, T.J. Predictors of relapse to heavy drinking in alcohol-dependent individuals after alcohol detoxification-The role of measures of quality of life, ethnicity, social class, cigarette and drug use. Addict. Biol. 1998, 3, 333-343. [CrossRef]

104. Brower, K.J.; Aldrich, M.S.; Robinson, E.A.; Zucker, R.A.; Greden, J.F. Insomnia, self-medication, and relapse in alcoholism. Am. J. Psychiatry 2001, 158, 399-404. [CrossRef] [PubMed] 